\title{
A Theoretic Revelation of Strategic Positioning, Value Co-Creation and Innovation Performance
}

\author{
Junlan Jia \\ School of Management, Shanghai University, Shanghai, 200444, China \\ jiajunlanjjl@163.com
}

Keywords: Strategic Positioning; Value Co-Creation; Innovation Performance; Grounded Theory; Case Study.

\begin{abstract}
In recent years, with the extensive use of $4 \mathrm{G}$ and wireless network technology, the development of mobile Internet industry has shown explosive growth, which leads to rapid development of intelligent mobile phone industry. The coming of a new era, not only changes people's way of life, study and work, but also gradually changes the mode of operation and the strategic layout of an enterprise. This paper takes Xiaomi Company as a research object, basing on Michael Porter's competitive advantage theory, product strategy model, and value co-creation theory, to analyze the characteristics of creating value while innovating of Xiaomi Company. Grounded Theory is used in this paper to explore the relations between strategic positioning, value co-creation and innovation performance.
\end{abstract}

\section{Introduction}

Xiaomi phone, which used to create network marketing legend and achieve overnight success, has brought us many surprises and thoughts. Xiaomi phone takes Internet as a carrier, to achieve point to point communication mode between enterprises and users and realize role transformation from customers to friends. Users are allowed to directly involve in the processes of product design, development and sales, which speeds up the rapid iteration of style and operating system. Winning and maintaining users by means of several platforms and constantly absorbing potential new users through good user experience and self-diffusion media leads to value co-creation and innovation performance between enterprise and users. Classical theories such as value creation, PEST model, Porter five forces model cannot perfectly explain why Xiaomi Company can produce products with ultra-low prices and high praise and why its sales volume can rank the third in the world in just four years. Therefore, researching on what methods Xiaomi company has used to realize its value and performance becomes a problem that is worth studying.

This study gets the knowledge of the characteristics and developing venation of the industry of Xiaomi phone through multi-level analysis on the internal and external environment, strategic positioning and innovation thinking of Xiaomi Company. Grounded Theory is applied in this study to arrive at Xiaomi Company's strategic positioning of user value with means of simplifying process, differentiation, low cost and reciprocal contract to realize strategic choices which realizes value cocreation and improvement of innovation performance between enterprises and users. This paper explores the logical relationship between strategic positioning, value co-creation and innovation performance, and attempts to make a contribution to this regard.

\section{Literature review}

Value Co-creation. Value creation is one of the core issues in enterprise strategies, and the change of main body of value creation will lead to the change of methods of value creation. The traditional view maintains that producers are the only creators who can create value, while consumers are the only consumers who consume value. However, according to the value co-creation theory, producers are not the only value creators, consumers are also not pure value consumers, but the co-creators interact with producers. Kambil et al (1996) defines value co-creation as a joint production process 
by which an enterprise and its customers realize the value together [1]. Ramirez (2000) argues that value is the product that enterprises and customers complete jointly [2].

Strategic Positioning Drives Innovation. The academism represented by Ander Ruth (1955) formulated a strategic model to look for solutions to match enterprises' internal abilities with the external environment opportunities [3]. Schumpeter believed that the fundamental phenomenon of economic development is innovation, and innovation not only refers to creating new things, but also includes combining or improving original things, this thesis is "creative destruction" [4].

\section{Design Research}

Research Method. Qualitative research is a method that utilizes the interaction study between researchers and the objects to make an in-depth and meticulous research, and then get a better comprehensive understanding of the nature of the matter. Grounded Theory is a method that combines theory with experience and links abstraction and concreteness, and founded by the American scholar Glaser and Strauss in the late 1960s. The core of Grounder Theory is the process of collecting and analyzing data. The process contains both theoretical deduction and theoretical summary [5]. Strauss calls data analysis of Grounded Theory "coding", that is an operation process which includes decomposing the literal data collected or translated, preliminarily analyzing the phenomena, then the phenomenon preliminarily conceptualized will be made conceptualized and abstracted for the second time [6]. Then make the concept abstract, advance and integrate for the third time in a proper manner, making it to be a category or core category. Grounded Theory research is aimed at describing the nature and meaning of phenomena from theoretical level, to establish a suitable theory for data and draw a relatively normative Grounded Theory by summing up and sorting out several kinds of literature data.

The purpose of this study is to explore how strategic positioning affect the value creation of companies in the perspective of innovation. A lot of theoretical research and practical exploration show that carrying out strategic management is the fundamental way to get sustainable competitive advantage in the complicated and changeable business environment, and strategic positioning is the core and soul of enterprise strategy management. This research uses the Grounded Theory method, basing on the collected real data and constant interaction between data and analysis, to continuously improve the theoretical sensitivity that refines new conclusion.

Case Study. In just five years, Xiaomi emerges from joint extermination of numerous mobile phone companies both at home and abroad and complete a luxuriant reversal from zero sales to forty billion dollars sales. This achievement is closely related to Xiaomi's action of seizing the needs of customers and keeping good interactive relation with them. In addition to mobile phones, all series of products have received consistent high praise, such as tablet computers, televisions, wrist strap, earphones, power supply, sockets, T-shirts and peripheral products [7]. Xiaomi Company has always been adhering to the idea of "born for burn", and produces whatever products customers need, designs whatever function customers need [8]. Users enjoy the fun of being respected and participating in the process. Now Xiaomi phone and the founder Lei Jun have become a phenomenon. There are many industries putting forward the slogan of "learning from Xiaomi". So it is necessary to study the product positioning of Xiaomi Company and understand the form of its value co-creation.

\section{Data analysis and findings}

The analysis process of Grounded Theory method can be divided into three main steps, open coding, axial coding and selective coding.

Open coding. Open coding refers to gradually conceptualizing and categorizing the data and record of an enterprise [9]. This is a process that downsizes a huge mass of data records step by step according to certain principles and properly reflects the content of data by the concept and category with the thorough breakdown, restructures, reorganization and induction of the data records and abstracted concepts. The aim of open coding is to identify the phenomenon, define the concepts and find out the category that is dealing with a convergence problem. To illustrate the process of opening 
coding, this research collects some a part of data records of Xiaomi Company, the examples of open coding recorded are shown in table 1.

Table 1 Examples of open coding

\begin{tabular}{|c|c|}
\hline The original data quoted & Initial category \\
\hline $\begin{array}{l}\text { Lei Jun expressed that the spell of Xiaomi is "mi". Firstly it represents Mobile } \\
\text { Internet, for Xiaomi eager to be a mobile internet company ; The second meaning } \\
\text { is mission impossible, Xiaomi will fulfill the tasks that are almost impossible be } \\
\text { completed; Finally, he hopes the sweet name "Xiaomi" can be a friend to everyone. } \\
\text { In addition, the new logo upside down of Xiaomi is a heart lacks of a point, which } \\
\text { means making users feel worry-saving. }\end{array}$ & $\begin{array}{l}\text { A name that is amiable, } \\
\text { easy to remember and } \\
\text { intimate. }\end{array}$ \\
\hline $\begin{array}{l}\text { "Design especially for Chinese habit" leads to the appearance of MIUI, which } \\
\text { gives customers a more intimate experience of smartphones. }\end{array}$ & $\begin{array}{l}\text { The style of design is } \\
\text { simple and practical. }\end{array}$ \\
\hline $\begin{array}{l}\text { Xiaomi products cover tablet computers, televisions, wrist strap, earphones, power } \\
\text { supply, sockets, T-shirts and peripheral products except mobile phones. }\end{array}$ & $\begin{array}{l}\text { The diversity of value } \\
\text { portfolio. }\end{array}$ \\
\hline $\begin{array}{l}\text { Online and offline activities, including "Popcorn", "city conference". More than } 20 \\
\text { official city conferences and } 500 \text { civil city conferences every year. }\end{array}$ & $\begin{array}{l}\text { Good interaction with } \\
\text { users, diverse } \\
\text { communication modes. }\end{array}$ \\
\hline $\begin{array}{l}\text { Li Wanqiang: the core of public praise of Xiaomi is "three and three of sense of } \\
\text { participation rules". }\end{array}$ & $\begin{array}{l}\text { Public participation in } \\
\text { product design. }\end{array}$ \\
\hline $\begin{array}{r}\text { Technicians will respond to the customers' sugg } \\
\text { minutes, and take improvement }\end{array}$ & $\begin{array}{l}\text { Effectiveness of } \\
\text { communication }\end{array}$ \\
\hline $\begin{array}{r}\text { Xiaomi company takes the form of network marketing, making } \\
\text { quickly and safely through proprietary and outsourcin }\end{array}$ & Convenience to buy \\
\hline The staff rewards and punishments are directly linked to customer feedback. & Customer feedback \\
\hline Adhere to the product idea of "born to burn". & Customer-drive \\
\hline Stick to one product, and use only one production line to reduce cost. & Low cost expansion \\
\hline Cut cost in advertising, return the saved costs to the users. & \\
\hline $\begin{array}{l}\text { High-grade configuration, big screen, replaceable batteries, solid and durable, good } \\
\text { signal, support multiple frequency bands, two sets of global positioning systems, } \\
\text { distinctive packaging, and the low-enough price. }\end{array}$ & $\begin{array}{l}\text { High performance-price } \\
\text { ratio }\end{array}$ \\
\hline $\begin{array}{l}\text { Desktop icon design is reasonable, advanced Android system, updates fast, } \\
\text { humanized, easy to operate, owns many personalized options and animation effect, } \\
\text { have diverse and innovative functions, two-dimension code. }\end{array}$ & $\begin{array}{l}\text { Software with humanized } \\
\text { design }\end{array}$ \\
\hline Provide "triathlon" services- software, hardware and internet service. & finition \\
\hline $\begin{array}{c}\text { BBS, advertisement, microblog interaction, Mi Fan festival, Coldplay group, "take } \\
\text { pictures at hand", "I am a mobile phone complex ", "make a breakthrough } \\
\text { bravely", activities in Tmall ,activities in Qzone. }\end{array}$ & Online activities \\
\hline $\begin{array}{l}\text { Develop MIUI system and Michat, the aim is earning reputatio } \\
\text { on spreading from mouth to mouth, have accumulated } 3 \text { milli }\end{array}$ & Users promotion \\
\hline City conference and "Xiaomi home" offline. & Offline activities \\
\hline $\begin{array}{l}\text { Directly sale through e-commerce, remove stores offline, face consumers directly, } \\
\text { don't depend on advertisement. Change the buyer-seller relationship from } \\
\text { consumers to friends. }\end{array}$ & Fans economy \\
\hline
\end{tabular}

Axial coding. Axial coding refers to applying a paradigm model to relate categories derived from open coding to each other. The process of this model includes causal conditions $\rightarrow$ phenomenon context $\rightarrow$ intermediary conditions $\rightarrow$ action/interaction strategy $\rightarrow$ results [10]. Paradigm model is an important analysis tool of Grounded Theory method, which is used to link categories together and excavate the meaning of category further. Making use of the conditions that generate an event (the main category), the context(that is the specific dimension indicators of the nature of the category) that this event depends on as well as strategies and the results that actors used to adopt in the event will help grasp the event (the main category) more accurately. Thus, even though the conditions, context, policies, and the results are also categories, they are related to one of the main categories and can be used to help understand the main category, so they are called vice categories.

In the phase of axial coding, four main categories were obtained by analyzing typical example, they are "make friends with users", "only produce hot series", "self-media marketing"," Internet thinking". 
Table 2. The results of axial coding

\begin{tabular}{c|c}
\hline Main categories & Vice categories \\
\hline \multirow{4}{*}{ Make friends with users } & A name that is amiable, easy to remember and intimate. \\
\cline { 2 - 2 } & The style of design is simple and practical. \\
\cline { 2 - 2 } & The diversity of value portfolio. \\
\cline { 2 - 2 } & Good interaction with users, diverse communication modes. \\
\cline { 2 - 2 } & Public participation in product design. \\
\cline { 2 - 2 } & Effectiveness of communication. \\
\cline { 2 - 2 } Only produce hot series & Convenience to buy \\
\cline { 2 - 2 } & Customer feedback \\
\cline { 2 - 2 } & Customer-drive \\
\cline { 2 - 2 } & Low cost expansion \\
\hline \multirow{3}{*}{ Self-media marketing } & Rebate to customers \\
\cline { 2 - 2 } & High performance price ratio \\
\cline { 2 - 2 } Internet thinking & Software with humanized design \\
\hline
\end{tabular}

Selective coding. Selective coding refers to a process that select the core category, contact it with other categories systematically, and verify their relationship, then complete the conceptual category that has not yet developed completely [11]. After studying on the four main categories (make friends with users, only produce hot series, self-media marketing, Internet thinking), deeply analyzing the corresponding vice categories and comparing with each other combined with raw data records, it will be found that the four main categories can be used to analyze other categories. The first three main categories are explained as user strategy, product strategy and marketing strategy. Xiaomi Company fully demonstrates the meaning of this concept and achieves the innovation performance and value co-creation on the base of full use of this three strategies, which greatly promotes the development and realization of the company value. The model of core categories are shown in Fig. 1.

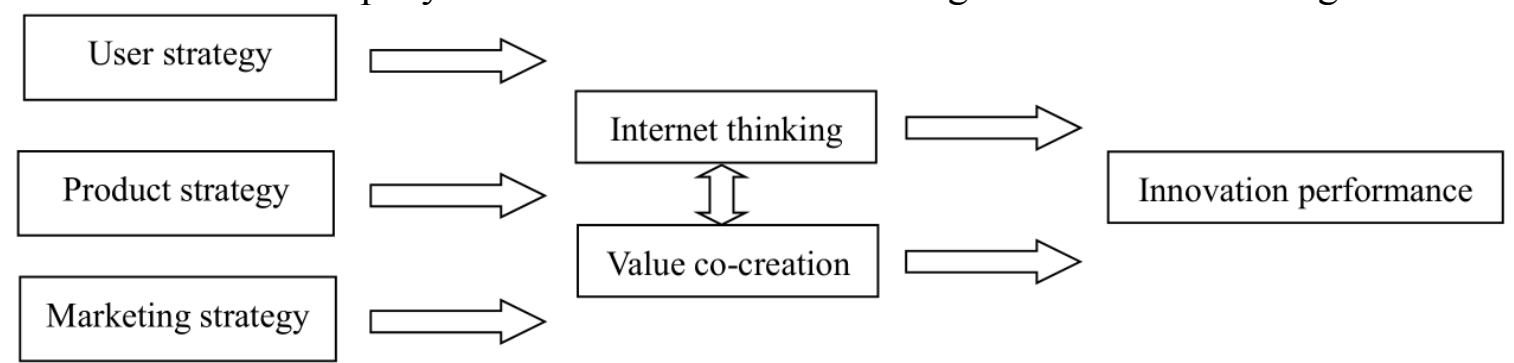

Fig. 1 Core categories model

\section{Conclusions}

According to the triple coding analysis of the Grounded Theory method, the results are as follows:

(1)Knowing what products to choose when product strategy is formulated. Xiaomi company focus on the idea of "born to burn", producing mobile phones with single form, devoting to create highquality goods, instead of establishing several series products to satisfy every customer like other mobile phone giants do. And the reason that Xiaomi can greatly control the cost and develop the Xiaomi phone known as "king of performance price ratio" is because they can change the situation of being restricted to distribution channel, suffering from profits exploitation and high advertisement cost that home-made mobile phones have faced by promoting micro-blogging marketing and online sale.

(2) Using Internet thinking reasonably. While the R\&D investment in hardware is strengthened, Xiaomi Company also spends a great effort into the software development work, especially in the development of their core software like MIUI and Michat. These software not only increases 
stickiness between Xiaomi Company and its users, but also turns the users into friends, and makes users be increasingly inseparable from the circle because of the usability, novelty of corresponding software. This is how Xiaomi consolidates its customer base. At the same time, the original good buzz marketing and the new customers form the common praise to the core competitiveness of Xiaomi phone together.

(3)Establishing Xiaomi ecosystem. Xiaomi company relies on Internet thinking, uses capital as the link and binds large amounts of hardware vendors after achieving scale effect to create an ecosystem with "service can be distributed, hardware can be shared, added-value with selling points", and then form a powerful enterprise "moat". If Xiaomi ecosystem can be applied to family life in the future, foreign competitors will be locked on the outside of the system, there is no escape route for them except for cooperating with Xiaomi.

In general, Xiaomi company uses new thinking perspective along with its proper strategic positioning (product strategy, user strategy, marketing strategy) and just one type of mobile phone to satisfy people's various needs, from the basic need of high performance-price ratio to high-level selfrealization with being respected and participation, to "herd mentality" that people desire to be accepted by others. The basic method to achieve innovation performance is co-creating value that is playing with fans rather than creating a perfect phone.

\section{References}

[1] Information on http://www.researchgate.net.

[2] R Ramirez, Value co-production: Intellectual origins and implications for practice and research, J. Strategic Management Journal. 1 (1999) 49-65.

[3] Xiang Baohua, Luo Qingjun, Andrews strategic thought and its extension, J. Science Research Management. 6 (2002) 1-6.

[4] Joseph Alois Schumpeter, The Theory of Economy Process, first ed., introduction, The Commercial Press, 1990.

[5] Zhang Jingwei, Ma Dongjun, Research method and management research of grounded theory, J. Modern Management Science. 2 (2009) 115-117.

[6] Anselm L. Strauss. Qualitative Analysis for Social Scientists, second ed., two illustrations, Cambridge University Press, 1987.

[7] He Lin, The development strategic research of Xiaomi company, D. Beijing University of Posts and Telecommunications. 2013.

[8] Liu Zengming, Liu Xize, Wang Yidan, Jiang Qiaofeng, Differentiation strategy and innovation management strategy analysis of Xiaomi phone , J. China Business and Trade. 6(2013)29.

[9] Fei Xiaodong, Grounded theory research methodology, J. Public Administration Review. 3 (2008) 23-43.

[10] Bai Changhong, Liu Chunhua, Study on similarities of internationalization strategy comparative of Haier and Huawei company based on the grounded theory, J. Science Research Management. 3 (2014) 99-107.

[11] Zhang Jingwei, Grounded theory method application in the management research, J. Science and Technology Management Research. 1(2010) 235-237. 